\title{
Vivências de uma Trabalhadora Rural: memórias sobre as transformações da/na paisagem ${ }^{1}$
}

\author{
Vivencias de una Trabajadora Rural: memorias sobre las \\ transformaciones de la/en la paisaje \\ Experiences of a Rural Worker: memories of the transformations of / in the
landscape
}

Daniele Brocardo ${ }^{2}$

\begin{abstract}
Resumo
Este trabalho vincula-se à pesquisa que está sendo desenvolvida para a construção de uma tese na área de História. Essa pesquisa objetiva estudar diversas percepções sobre as transformações da/na paisagem que abrange o ecótono da Floresta Ombrófila Mista-FOM com a Floresta Estacional Semidecidual-FES, na região que compreendia o munícipio de Cascavel, no estado do Paraná, entre as décadas de 1950 a 1990. Essas transformações ocorreram a partir, principalmente, das ações de indústrias madeireiras e da agricultura. Deste modo, através da metodologia da História Oral, dialoga-se nesse texto com uma entrevista realizada com a senhora Lurdes Zancanaro Manica, que trabalhou na agricultura e na pecuária, no período e espaço estudados, atuando em diversas propriedades, juntamente com seu marido, já falecido. Espera-se com essa entrevista, considerar algumas de suas memórias construídas como uma mulher trabalhadora rural e as percepções apresentadas sobre as mudanças da/na paisagem. Destarte, o foco do texto ocorre sobre as relações: humanos/meio natural, divisão do trabalho familiar, a vida e o trabalho na agricultura e na pecuária.
\end{abstract}

Palavras-Chave: Memórias; Relação Humanos/Meio Natural; Trabalho Agrícola; Vida no Campo.

\section{Resumen}

Ese trabajo se relaciona a la investigación que esta siendo desarrollada para la construcción de una tesis en el área de la Historia. Esa investigación tiene por objetivo estudiar las distintas percepciones sobre las transformaciones de la /en la paisaje que abarca el ecotono de la Floresta Ombrófila Mista-FOM con la Floresta Estacional Semidecidual-FES, en la región que abarcaba el municipio de Cascavel, en el departamento del Paraná, entre las décadas de 1950 a 1990. Esas transformaciones ocurrieron, principalmente, desde las acciones de industrias madereras y de la agricultura. De este modo, a través de la metodología de la Historia oral, este texto dialoga con una entrevista hecha con la señora Lurdes Zancanaro Manica, que trabajó en la agricultura y en la ganadería, en el periodo y espacio estudiados, laburando en distintas propiedades, junto con su marido, ya fallecido. Se espera con esa entrevista, tener en cuenta algunas de sus memorias construidas como una mujer trabajadora rural y las percepciones presentadas sobre los cambios de la /en la paisaje. De esta manera, el enfoque del texto ocurre sobre las relaciones: humanos/medio natural, división del trabajo familiar, la vida y el trabajo en la agricultura y la ganadería.

Palabras claves: Memorias; Relaciones Humanas/Medio Natural; Trabajo Agrícola; Vida en el Campo.

\footnotetext{
Abstract

This work is linked to the research being developed for the construction of a History PhD thesis. This research aims to study several perceptions about the transformations of / in the landscape that encompasses the ecotone of

${ }^{1}$ Artigo apresentado no Simpósio Temático (ST 13 - Cultura, Fronteira e Relações Internacionais) durante o II Seminário Latino-Americano de Estudos em Cultura - SEMLACult em Foz do Iguaçu/PR, Brasil, 2018.

2 Doutoranda do Programa de Pós-Graduação em História da Universidade Estadual do Oeste do ParanáUNIOESTE, Linha de pesquisa Cultura e Identidades, Marechal Cândido Rondon, Paraná, Brasil; e-mail: danielebrocardo@gmail.com. O presente trabalho foi realizado com apoio da Coordenação de Aperfeiçoamento de Pessoal de Nível Superior - Brasil (CAPES) - Código de Financiamento 001.
} 
the Araucaria forest with the Atlantic Semideciduous forest, in the region comprised the municipality of Cascavel, in the state of Paraná, between 1950 and 1990. These transformations occurred mainly from timber industry actions and agriculture. In this way, through the Oral History methodology, an interview with Mrs. Lurdes Zancanaro Manica, who worked in agriculture and livestock, during the period and space studied, on several properties with her husband, already deceased. It is hoped by this interview, to consider some of her memories built as a rural working woman and the perceptions presented about the changes of the landscape. Thus, the focus of the text is on relations: human / natural environment, division of family work, life and work in agriculture and livestock.

Keywords: Memoirs; Human Relationship / Natural Environment; Agricultural Work; Life in the Field.

\section{Introdução}

Este artigo vincula-se à pesquisa que está sendo desenvolvida para a elaboração de uma tese na área de História. A partir dela, visa-se abordar diversas percepções sobre as transformações da/na paisagem que abrange o ecótono ${ }^{3}$ da Floresta Ombrófila Mista-FOM com a Floresta Estacional Semidecidual-FES, na região que compreendia o munícipio de Cascavel $^{4}$, no estado do Paraná, entre as décadas de 1950 a 1990. Essas transformações ocorreram, principalmente, a partir das ações de indústrias madeireiras e da agricultura.

Assim, neste texto dialoga-se com uma entrevista, realizada com Lurdes Zancanaro Manica que trabalhou na agricultura e na pecuária, no período e espaço estudados. Com o objetivo de se considerar algumas das memórias construídas por uma trabalhadora rural e as percepções apresentadas sobre as mudanças na paisagem, analisando os olhares que se pode ter sobre o meio natural.

Na pesquisa utilizamos o conceito de paisagem, é a partir do que Simon Schama (1996, p.17) escreveu em seu livro Paisagem e Memória que delimitamos este conceito:

[...], conquanto estejamos habituados a situar a natureza e a percepção humana em dois campos distintos, na verdade elas são inseparáveis. Antes de poder ser um repouso para os sentidos, a paisagem é obra da mente. Compõe-se tanto de camadas de lembranças quanto de estratos de rochas.

A partir dessas colocações, a paisagem é entendida como interação entre o meio e a ação humana, sendo visualizada, sentida e ouvida, constituindo-se, dessa forma, em uma realidade interpretada pela percepção humana. Tudo que dizemos, escrevemos ou

\footnotetext{
${ }^{3}$ Este conceito pode ser definido, de forma concisa, como: "transição entre dois ecossistemas diferentes e tensão entre ambos." (MILAN; MORO, 2016, p.76.)

${ }^{4}$ A reocupação da área que hoje forma o município de Cascavel/PR iniciou na década de 1930, aliada a um projeto de ocupação de fronteiras em âmbito nacional. Até o ano de 1951, permaneceu como distrito de Foz do Iguaçu. A criação do município se deu por meio da Lei estadual 790/51, com sua efetivação em 14 de dezembro de 1952. Inicialmente seu território foi delimitado, ao norte, pelo Rio Piquiri e, ao sul, pelo Rio Iguaçu, mas com o decorrer dos anos o tamanho desse território foi reduzido devido à criação de novos municípios .
} 
fotografamos sobre o meio natural passa por nossa percepção, pois a natureza não cria significados sobre ela mesma (SCHAMA, 1996, p.17).

Os autores Angelo A. Priori e Letícia A. Paixão (2015, p.163-164) destacaram também as ligações que os seres humanos estabelecem com a paisagem a partir da memória, como: “dimensão afetiva”, de "pertencimento", mas não só de "mero prazer”. “A paisagem é o lugar de projeções e simbolizações de sentimentos e ações humanas, bem como o lugar onde se articulam o social e sua representação, a matriz simbólica onde a experiência coletiva se enraíza e se reflete ao mesmo tempo" (PRIORI; PAIXÃO, 2015, p.166).

Assim, se a paisagem é a junção do que uma pessoa pensa, suas memórias, com o meio onde vive, também é parte da paisagem a vegetação que forma o espaço do estudo. Essa era, antes das transformações, composta pelo ecótono da Floresta Ombrófila Mista - FOM com a Floresta Estacional Semidecidual - FES (ambas pertencentes ao bioma da Mata Atlântica). A FOM é denominada, também, de Mata dos Pinheiros, pois é a Araucaria angustifólia a espécie que caracteriza essa vegetação. Já a FES é constituída por espécies como: Peroba-Rosa, Pau-Marfim, Cedro e Palmeiras.

As transformações nessa vegetação estão relacionadas ao período que marcou as ações de madeireiras e da agricultura de forma mais intensa no município de Cascavel, as décadas de 1950 a 1990. As três primeiras décadas -1950 a 1970 - se constituíram em um período de maior atividade das madeireiras, que atuavam em conjunto com a agricultura. Já nas duas últimas - 1980 a 1990 - ocorreu uma intensificação da ação da agricultura, se consolidando como atividade econômica predominante em relação às madeireiras.

A partir das ações de madeireiras e da agricultura para as transformações da/na paisagem, propõe-se investigar diversas percepções sobre esse processo. Assim, podemos definir brevemente o conceito de percepção a partir da obra Topofilia: um estudo da percepção e valores do meio ambiente de Tuan (1980, p.04), como sendo:

[...] tanto a resposta dos sentidos aos estímulos externos, como a atividade proposital, na qual certos fenômenos são claramente registrados, enquanto outros retrocedem para a sombra ou são bloqueados. Muito do que percebemos tem valor para nós, para a sobrevivência biológica, e para propiciar algumas satisfações que estão enraizadas na cultura.

Destarte, é partir da análise de uma entrevista de História oral que procuramos estudar algumas percepções sobre as transformações da paisagem. Sobre essa fonte e metodologia utilizadas, cabe dizer que a História oral permite compreender que as percepções sobre o meio natural devem ser analisadas levando em consideração o tempo e o espaço em que o sujeito 
está inserido, no momento de sua ação, no passado, e no momento de sua recordação, no presente.

Assim, entende-se que as ações de transformações da paisagem são relatadas conforme a experiência de cada indivíduo. Porém, as narrativas, não operam como algo isolado do restante da sociedade.

Procuramos estudar a fonte oral como escreveu Yara A. Khoury (2006, p.31), sendo as fontes orais pensadas para "além das características informativas", são consideradas a partir das "características interpretativas, por meio das quais cada um se situa na realidade social; fomos tomando as narrativas como textos impregnados de significados [...]", a partir da relação passado e presente. Também, tentamos pensar as entrevistas como um diálogo:

\begin{abstract}
Caminhar nessa direção tem significado lembrar sempre que incorporar com legitimidade a fala daqueles que entrevistamos, e considera-las devidamente como atos interpretativos da realidade que estudamos; é lembrar que as entrevistas orais, por sua própria natureza, não se fazem com técnicas e, sim, com relações humanas em que estamos desejosos de conhecer melhor como cada pessoa vive e constrói essa luta, ou mesmo se submete. Tem significado, também, trazer essas narrativas para dentro de nosso texto numa relação de igualdade (KHOURY, 2006, p.32).
\end{abstract}

Mesmo sabendo que essa relação de troca não é tarefa fácil, é a partir dessas reflexões que pensamos a análise da entrevista. Contudo, cabe ainda dizer como pensamos o conceito de memória, pois quando trabalhamos com entrevistas, essa também deve ser considerada. A partir de Pollak (1992, p.201-203), entendemos a memória como "um fenômeno coletivo e social”, que está "submetido a flutuações, transformações, mudanças constantes", mas também como "fenômeno individual". Igualmente, é ainda compreendida como "fenômeno construído", consciente ou inconscientemente, produto de um trabalho de organização e seleção. Assim, a partir destas considerações, realizadas acima, podemos passar para a análise da entrevista.

\title{
2. "Eu tenho saudade do tempo da roça, parece que era bem mais divertido né!?" (ZANCANARO MANICA, 2018, s/p)
}

A entrevista foi realizada com Lurdes Zancanaro Manica ${ }^{5}$, no dia 17 de abril de 2018, em sua residência no distrito Juvinópolis, pertencente ao município de Cascavel/PR. Ela nasceu em 06 de agosto de 1944, no município de Passo Fundo/RS, e mudou-se no de 1966

\footnotetext{
${ }^{5} \mathrm{O}$ contato com a entrevistada se deu através de minha mãe, já que Lurdes Zancanaro Manica foi casada com um irmão de meu avô materno.
} 
para o espaço do estudo, é uma ex-empregada de diversas fazendas. No momento da entrevista, residia em sua casa própria, com sustento de sua aposentadoria.

Lurdes Zancanaro, como se apresentou, apesar de possuir também o sobrenome de seu marido, já falecido, Severino Vitorio Manica, com quem se casou no município de Tapejara/RS, com 21 anos. No momento da entrevista estava com 74 anos, possui 5 filhos, 3 mulheres e 2 homens. Queixou-se do fato de seus filhos levarem somente o sobrenome do pai: "só tem Manica, não tem Zancanaro nenhum dos meus filhos" (ZANCANARO MANICA, 2018, s/p). Ela também, possui 10 netos e 4 bisnetos.

Além destes filhos, teve outra menina, que faleceu ainda bebê, com nove meses. No período do falecimento de sua filha, Lurdes Zancanaro trabalhava em seu segundo emprego ${ }^{6}$ no município de Cascavel, uma fazenda pertencente a um comandante das forças aéreas. A entrevistada contou que devido à distância, já que o hospital mais próximo ficava no município vizinho de Catanduvas/PR, e a falta de condições, como um veículo, no caminho para o hospital sua filha falecera: “-[...] morreu lá no Tormenta, ali no passar o rio [...]” (ZANCANARO MANICA, 2018, s/p).

Na sequência, de sua fala, exaltou: "Era sofrido, mas era tudo mais fácil, parece que qualquer coisa servia. Agora hoje em dia que está mais difícil tudo" (ZANCANARO MANICA, 2018, s/p). É interessante pensar que há uma comparação do passado com o presente, e nessa confrontação, mesmo quando o passado parece mais triste e difícil, (sem um hospital por perto, nem remédios, ou estradas e um transporte, o que levou a perda de sua filha), Zancanaro, ainda exaltou o presente, como sendo ainda mais complicado. Talvez, isso ocorreu porque o momento da entrevista seja o presente, nossas recordações do passado estão carregadas de percepções do presente.

De tal modo, ela estava pensando no presente, em relação à burocracia. Já que seguiu sua narrativa falando da dificuldade de um dos seus netos para fazer a carteira de trabalho, em relação à morte de sua filha, a qual na ocasião não foi necessário, imediatamente, o atestado de óbito.

Ao longo da entrevista Zancanaro fez questão de falar um pouco sobre com estão cada um de seus filhos e netos. Sobre seus trabalhos, narrou que suas filhas ainda moram e trabalham em fazendas e seus dois filhos trabalham no espaço urbano. Ao falar sobre a morte de familiares exaltou:

\footnotetext{
${ }^{6}$ Seu primeiro emprego também foi em uma fazenda pertencente a o ex-prefeito de Cascavel/PR, Salazar Barreiros.
} 
Lurdes Zancanaro Manica (2018, s/p): É morre os mais novos e ficam os mais velhos, que comeram mais feijão [risos]. Eles aguentam mais, é que eu acho que agora tá mais difícil por causa dessas coisas, muito veneno, muito veneno, por que a gente, no tempo da gente, plantava, era feijão sem veneno, milho sem veneno, não se colhia nada com veneno. Agora hoje em dia plantam tudo e matam tudo com veneno, pra depois colher.

Lurdes Zancanaro se referiu há outro tempo, no qual: plantavam, colhiam e se alimentavam, de forma diferente da atual. Assim, novamente, ocorreu uma comparação do passado a partir do presente, mas, dessa vez, o passado que foi valorizado. Segundo Milton Santos (2004, p.88.): "Desde o princípio dos tempos, a agricultura comparece como atividade reveladora das relações profundas entre as sociedades humanas e o seu entorno". Deste modo, através da agricultura e do passar do tempo, a entrevistada percebeu as mudanças nessas relações.

Essas mudanças, que se somam a outras alterações socioambientais, são fruto da modernização da agricultura, estabelecida, sobretudo, após o golpe de 1964 no Brasil e acarretaram na instalação de "uma agricultura propriamente científica, responsável por mudanças profundas quanto à produção agrícola e quanto à vida de relações" (SANTOS, 2004, p.88.). Também, tornaram o Brasil, "nos dias de hoje, o maior consumidor mundial de agrotóxicos" (ALENTEJANO, 2012, p. 480) e o município de Cascavel em primeiro lugar no Estado do Paraná ${ }^{7}$.

$\mathrm{Na}$ narrativa essas mudanças observadas na agricultura ocasionam em impactos à saúde humana. Segundo o Atlas do Agronegócio, as intoxicações agudas por agrotóxicos (ou veneno) "afetam principalmente as pessoas expostas em seu ambiente de trabalho", ou seja, trabalhadores agrícolas como Lurdes Zancanaro, ou agricultores. Entre os sintomas dessas intoxicações, estão: “[...] irritação da pele e dos olhos, coceira, vômitos, diarreias, dificuldades respiratórias, convulsões e morte” (SANTOS; GLASS, 2018. p. 22.).

No entanto, os agrotóxicos, também acarretam em intoxicações crônicas, sendo essas “[...] decorrentes da presença de resíduos de agrotóxicos em alimentos e no ambiente, geralmente em doses baixas", assim, afetado toda população. Alguns danos desses tipos de intoxicações são: “infertilidade, impotência, abortos, malformações, neurotoxicidade, desregulação hormonal, efeitos sobre o sistema imunológico e câncer” (SANTOS; GLASS, 2018. p. 22.).

\footnotetext{
7 Dados referentes ao ano de 2013 . em: <http://www.saude.ufpr.br/portal/observatorio/monitoramento/mapas-do-consumo-de-agrotoxicos-noparana/>. Acesso. 13/02/2019.
} 
O dossiê da Associação Brasileira de Saúde Coletiva (Abrasco) também apresenta através de pesquisas os impactos do uso de agrotóxicos na saúde. Segundo o dossiê "um terço dos alimentos consumidos cotidianamente pelos brasileiros está contaminado pelos agrotóxicos", além disso, "parte dos agrotóxicos utilizados tem a capacidade de se dispersar no ambiente, e outra parte pode se acumular no organismo humano, inclusive no leite materno" (CARNEIRO, et al, 2015, p. 58; 74.). No entanto:

Há muitas lacunas de conhecimento quando se trata de avaliar a multiexposição ou exposição combinada a agrotóxicos. A grande maioria dos modelos de avaliação de risco serve para analisar apenas a exposição a um princípio ativo ou produto formulado, ao passo que no mundo real as populações estão expostas a misturas de produtos tóxicos cujos efeitos sinérgicos (ou de potencialização) são desconhecidos ou não são levados em consideração. Além da exposição mista, as vias de penetração no organismo também são variadas, podendo ser oral, inalatória e ou dérmica simultaneamente. Essas concomitâncias não são consideradas nos estudos experimentais mesmo diante da possibilidade de que exposições por diferentes vias modifiquem a toxicocinética do agrotóxico, podendo torná-lo ainda mais nocivo (CARNEIRO, et al, 2015, p. 76.).

Deste modo, provavelmente, as percepções apresentadas por Lurdes Zancanaro Manica, não são totalmente baseadas na "ciência moderna", elas operam mais com base em seu conhecimento composto: de suas vivências em sociedade, do trabalho na agricultura e das relações a partir do passar do tempo. Podemos pensar no que escreveu Arruda (2000, p. 60.):

A apreensão dos fenômenos da natureza, hoje em mãos do discurso científico, como a meteorologia, geologia, cartografia, etc., também pode ser pensada em termos de uma tradição baseada na experiência. É válido lembrar o "notório" saber que os "antigos" tinham sobre os fenômenos naturais, seu senso de direção e orientação espacial, que foi sistematicamente negado pela "ciência". Esses saberes populares fazem parte de um conjunto maior que poderíamos chamar de "memória coletiva da natureza", ou de "horizonte espacial coletivo" e, como tal, propiciar ao historiador um rico veio de pesquisa sobre a "mentalidade popular" e suas relações conflituosas com os "saberes científicos", ou com os valores da modernidade.

Assim, os elementos que descrevem uma produção agrícola e uma alimentação, em moldes diferentes das operantes na atualidade, vão aparecer mais vezes na narrativa de Lurdes Zancanaro. Deste modo, narrou:

Lurdes Zancanaro Manica (2018 s/p): A minha mãe mesmo morreu com essa idade e não se via uma latinha de comida comprada dentro da casa dela, morava no sítio, daí ela fazia, se era pra fazer um doce era das frutas dela lá e daí tinha tudo, a hortinha, tinha de tudo lá na horta e era pouquinha terra que eles tinham, só tinham três alqueires, depois que o falecido pai morreu, eles sempre arrendavam terra, mais depois ficou só o meu irmão com a mãe, daí eles se viraram naquele [terreno] mesmo, pedacinho de terra, dava pra viver.

Daniele Brocardo: E plantavam o que seus pais? O que eles plantavam mais? 
Lurdes Zancanaro Manica: O tempo que nós era solteiro lá, que eu morei 21 anos junto só depois casei, nós sempre plantava arroz, até poucos anos eles plantavam arroz, arroz, feijão, era milho, daí a gente plantava fumo também, daí mudou pro fumo também.[...]

Lurdes Zancanaro Manica: Não se usava nada de veneno, nem nas muda de fumo, era tudo plantado sem veneno e plantava tudo sem veneno e o falecido pai tinha muita abelha. Daí nós tinha bastante abelha, dava muito mel.

Zancanaro Manica (2018, s/p) narrou também que essa produção era vendida para os vizinhos ou consumido pela própria família. Portanto, o modo de produção agrícola descrito: de subsistência, de policultura e marginal aos princípios do mercado, já não faz parte do presente. Nesse, em oposição, a produção segue a lógica total do mercado, voltada para exportação de monoculturas, com uso excessivo de venenos. Ou como escreveu Milton Santos (2004, p.89):

Nas áreas onde essa agricultura científica globalizada se instala, verifica-se uma importante demanda de bens científicos (sementes, inseticidas, fertilizantes, corretivos) e, também, de assistência técnica. Os produtos são escolhidos segundo uma base mercantil, o que também implica uma estrita obediência aos mandamentos científicos e técnicos. São essas condições que regem os processos de plantação, colheita, armazenamento, empacotamento, transportes e comercialização, levando à introdução, aprofundamento e difusão de processos de racionalização que se contagiam mutuamente, propondo a instalação de sistemismos, que atravessam o território e a sociedade, levando, com a racionalização das práticas, a uma certa homogeneização.

Tal homogeneização também passa fazer parte da alimentação da população. Já que: “estima-se que os povos pré-históricos alimentavam-se de mais de 1.500 espécies de plantas e que pelo menos 500 dessas espécies e variedades têm sido cultivadas ao longo da história. Atualmente, apenas 30 vegetais cultivados perfazem 95\% da dieta humana, e o trigo, arroz, milho e soja representam mais de 85\% do consumo de grãos" (MAICÁ, 2012, p. 700.). Temos, portanto, uma transformação na alimentação humana, que parte de uma transformação na paisagem.

Essas transformações na alimentação humana foram percebidas pela entrevistada, a partir das lembranças sobre sua mãe. Deste modo, foi a partir da Revolução verde que tinha como objetivo "intensificar a oferta de alimentos [...] a fim de solucionar a fome no mundo, visto que na época se considerava a pobreza, e principalmente a fome, como um problema de produção" (PEREIRA, 2012.p. 687.), que tivemos essas mudanças na alimentação humana.

A Revolução verde, além de não acabar com a fome no mundo - visto que esse problema não está na quantidade de alimentos produzidos, mas na desigual distribuição ainda inseriu: "os organismos geneticamente modificados que hoje dominam boa parte da 
agricultura também trouxeram incertezas e preocupações por parte, principalmente, dos consumidores, que temem pela sua saúde com o consumo de organismos transgênicos" (MENDONÇA, 2014, p. 02). Além disso:

O refinamento dos alimentos, o "empacotamento" dos mesmos, o crescimento e maturação forçados, o uso de produtos químicos, organismos geneticamente modificados (OGMs), e entre tantas outras transformações vieram para acelerar todos os processos, deixar os alimentos aparentemente mais bonitos, com maior durabilidade, com maior praticidade (semi-prontos ou prontos) enquanto que a produção natural de cultivares de espécies animais e vegetais reduzem o seu tempo natural de desenvolvimento. [...] (CONTE, 2016, p. 71.).

Podemos pensar somente na produção de fumo (tabaco), de como foi descrita por Zancanaro e como ocorre no presente, após os efeitos da Revolução verde. Se antes nessa produção não se utilizava agrotóxicos, atualmente, "são usados em média 60 litros de agrotóxicos por hectare dessa lavoura" (SANTOS; GLASS, 2018. p. 22.). Além disso, na descrição o fumo, como as demais culturas, eram consumidas pela própria família ou vendidas para os vizinhos, hoje produção de fumo no sul do Brasil ocorre, sobretudo com controle total das empresas de tabaco, no Sistema Integrado de Produção do Tabaco (SIPT), descrito por alguns autores como servidão moderna (ALMEIDA, 2005), pois:

[...] As atividades são realizadas manualmente, exigindo a execução de movimentos repetitivos e a adoção de posturas forçadas durante longos períodos, que implicam distúrbios osteoarticulares. Exceto durante as etapas de cura/secagem e pré classificação, todas as demais atividades são realizadas sob céu aberto, expondo as pessoas envolvidas às intempéries e ao risco de adoecimento por doenças provocadas pela radiação solar, como câncer de pele. A larga utilização de agrotóxicos, de diversas classes toxicológicas, expõe as famílias produtoras ao risco das intoxicações agudas e crônicas. Os trabalhadores e as trabalhadoras ficam expostos à nicotina presente nas folhas do tabaco, principalmente na época da colheita, o que resulta na doença da folha verde do tabaco. [...].

O Sistema Integrado de Produção do Tabaco (SIPT) regula as relações entre famílias produtoras e as empresas fumageiras, por intermédio de contratos de compra e venda da produção. Por meio desse contrato cabe às empresas a governança das atividades, com fornecimento de insumos (agrotóxicos, fertilizantes etc.), prestação de assistência técnica e classificação final do produto para o pagamento da produção, entre outras obrigações. [...] (MARCELO, 2017, p. 49.).

Assim, nessa nova forma de produção do fumo os agricultores além de estarem sujeitos aos problemas de saúde, causados pelos agrotóxicos e a nicotina, ainda tem sua produção limitada pelos interesses das empresas que estabelecem contrato para a venda do produto. A entrevistada demostrou ter uma percepção bastante crítica sobre essas mudanças.

É interessante pensar porque Zancanaro conectou a produção de alimentos com a criação de abelha. Será que ela tem conhecimento que são esses insetos os principais 
responsáveis pela polinização, tanto dos remanescentes de florestas, como de plantas cultivadas? Mas, também, que a ciência atual, aponta o uso de agrotóxicos em larga escala como o causador do desaparecimento de várias espécies de abelhas e que a "[...] segurança alimentar global está ameaçada pelo declínio das abelhas manejadas e pela perda de polinizadores selvagens, no Brasil chamadas de abelhas indígenas sem ferrão [...]"(NOCELLI. et al., 2012, p.199.)? Talvez, novamente, sua percepção esteja mais baseada em suas vivências.

Em seguida Zancanaro recordou que seu pai tinha muitas abelhas, e que depois de sua morte as abelhas também morreram, já que só seu pai possuía a paciência necessária para lidar com as abelhas. Seguiu a sua narrativa comparando o trabalho com as abelhas, com o trabalho com as vacas: "Mesma coisa com uma vaca brava, se você vai mexer com uma vaca brava e se você ter medo ela vai atrás, senão ela não vem" (ZANCANARO MANICA, 2018, $\mathrm{s} / \mathrm{p})$.

Tal trabalho permeou boa parte de sua vida, e ainda faz parte de seus sonhos, como narrou: -“[...] esses dias eu estava sonhando bem com as minhas [vacas] que vendi por último, parece que eu estava mexendo com tudo elas, digo: - 'Ai! fiquei faceira', me acordei, digo: 'i! estou na cama, nem tenho vaca nada!' [rindo]” (ZANCANARO MANICA, 2018, s/p) . Podemos perceber o valor que a entrevistada atribuiu ao trabalho com as vacas, não só por sua fala, mas, também por um porta-retratos com uma fotografia de uma vaca que está em sua estante da sala, junto a outros porta-retratos com as fotografias de seus familiares.

Deste modo, narrou algumas de suas vivências relacionadas ao trabalho com as vacas, e exaltou: - "Eu tenho saudade do tempo da roça, parece que era bem mais divertido né!? Bom agora se eu fosse pra ir não aguento mais, fui carpir a horta, foi quarta passada, quando foi quinta não conseguia caminhar" (ZANCANARO MANICA, 2018, s/p). Nesse trecho o passado é interpretado como um período melhor, não só pelo seu trabalho como as vacas, mas, também pela juventude.

Sobre esse trabalho ainda narrou:- "Eu nunca corri de vaca". Desta forma mostrou o enfretamento e coragem em seu trabalho. Porém, lembrou uma única vez que uma vaca a atacou, completou sua fala dizendo: "não é fácil mexer com os bichinhos" (ZANCANARO MANICA, 2018, s/p). Podemos pensar novamente, através de sua fala, a valorização de seu trabalho.

Neste sentido, Lurdes Zancanaro, falou sobre os diferentes lugares que trabalhou, contou algumas vivências que teve em cada um desses trabalhos, seja tirando leite, para vender, ou para fazer queijo, enquanto seu marido fazia cerca de arame farpado, ou, ainda, 
quando cuidava de cabritos soltos que fugiam, ou, fazendo roça de milho. Em seguida descreveu quando se mudou a primeira vez, para a casa onde reside hoje, e quando seu esposo quis mudar novamente:

\begin{abstract}
Lurdes Zancanaro Manica (2018, s/p): [...] daí ele veio pra casa: "mulher, vamos mudar", digo: "você vai mudar, você me prometeu que não ia mais mudar e eu recém terminei de arrumar a minha mudança", 40 dias bem certo nós estava saindo denovo. Daí, briguemos a noite inteira, [ele]: "vai!?”, [ela]: "não vou”, [ele]: "vai mulher, porque nós vamos ganhar dois salários e nós temos as nossas vacas lá e tem não sei o que e o homem é bom e não sei o que", digo: "eu vou pensar até amanhã cedo",[...] [ela]: "homem eu não te disse se eu vou ou não vou, eu não estou afim de ir", mas eu fazia proposta só pra ver ele bravo, mas daí ele ficou bravo, daí fungava, digo: "tá bom tá pare de fugar que vamos" [rindo].
\end{abstract}

Podemos analisar que ao narrar essa vivência Zancanaro procurou demostrar que mesmo acolhendo às escolhas de seu marido, ainda assim, não deixava de apresentar que também tinha uma opinião, que não atendia de pronto o que ele propunha para a vida de ambos e dos filhos. Mesmo que isso gerasse alguma discussão. Também, observamos nessa fala, que sua vida, como de outros empregados agrícolas, foi feita de constantes mudanças, para novos lugares em busca de emprego.

Todavia, esse trecho é aqui, também, apresentado com o intuito de demostrar, que por mais que uma narrativa esteja sendo estudada dentro de um projeto de pesquisa, ela traz elementos que possibilitam outras análises, que não se restringem a um único objetivo de pesquisa. Como escreveu Alessandro Portelli (2016, p.20.):

Por outro, a forma narrativa sempre contém mais camadas de significado, mais caminhos de interpretação do que uma análise lógica, racional. Embora nós não nos abstenhamos de desenvolver hipóteses e de sugerir interpretações, estamos cientes do fato de que o material que apresentamos pode sempre ser lido de outras maneiras.

Assim, a narrativa de Lurdes Zancanaro possibilita pensar as percepções sobre as transformações na paisagem, e como isso alterou, também, a alimentação e a saúde dos seres humanos. Além disso, sua fala possibilita analisar as diferentes vivências de uma trabalhadora do meio rural, como as ligações construídas com os animais e as constantes mudanças de empregos. Porém, há, também, em sua narrativa, ponderações sobre as diferentes condições deste trabalho, ligadas a diferentes fatores, como o gênero, já que as mulheres tinham um trabalho, os homens outros.

\title{
Referências
}


ALENTEJANO, Paulo. Modernização da Agricultura. In: CALDART, Roseli Salete. et al (org.). Dicionário da Educação do Campo. Rio de Janeiro, São Paulo: Escola Politécnica de Saúde Joaquim Venâncio, Expressão Popular, 2012. p. 479-483.

ALMEIDA, G. E. G. Fumo: servidão moderna e violação de direitos humanos. Curitiba: Terra de Direitos, 2005.

ARRUDA, Gilmar. Representações da natureza: história identidade e memória. In: ROLIM, Rivail C.; PELEGRINI, Sandra A.; DIAS, Reginaldo (Orgs). História, Espaço e Meio Ambiente. Maringá: ANPUH-PR. 2000, p.43-65.

CARNEIRO. F.F. et al (Org.). Dossiê ABRASCO: um alerta sobre os impactos dos agrotóxicos na saúde. Rio de Janeiro/ São Paulo: Expressão Popular, 2015.

CONTE, Franciéli Aline. Efeitos do consumo de aditivos químicos alimentares na saúde humana. Revista Espaço Acadêmico, Maringá, no 181, ano XVI, p.69-81, 2016.

KHOURY, Yara A. O historiador, as fontes orais e a escrita da história. In: ALMEIDA, P. R. de; KHOURY Y. A.; MACIEL, L. A. (orgs.). Outras histórias: memórias e linguagens. São Paulo: Olho d' Água, 2006. p.22-43.

MAICÁ, Eitel Dias. Sementes. In: CALDART, Roseli Salete et al (org.). Dicionário da Educação do Campo. Rio de Janeiro, São Paulo: Escola Politécnica de Saúde Joaquim Venâncio, Expressão Popular, 2012. p.699-706.

MARCELO, Moreno dos Reis, et al. Conhecimentos, atitudes e práticas de agricultoras sobre o processo de produção de tabaco em um município da Região Sul do Brasil. Cad. Saúde Pública [online], vol.33.p.148-161. 2017. Disponível em:〈http://www.scielo.br>.

MENDONÇA, Fernanda Graebin. Alimentos Transgênicos $x$ Alimentos de Qualidade: os desafios jurídicos para a garantia do direito humano à segurança alimentar. 2014. Disponível em: <http://www.publicadireito.com.br/artigos/?cod=9fa382e159884a63 >. Acesso em: 20/02/2019.

NOCELLI, R. C. F. et al. Riscos de Pesticidas sobre as Abelhas. In. Semana dos Polinizadores, 3, 2012, Petrolina Anais. Palestras e resumos: Embrapa Semiárido. Disponível em: <https://ainfo.cnptia.embrapa.br/digital/bitstream/item/69299/1/Roberta.pdf $>$. Acesso: 26/04/2019.

PEREIRA, M. C. de B. Revolução Verde. In: CALDART, Roseli Salete et al (org.). Dicionário da Educação do Campo. Rio de Janeiro, São Paulo: Escola Politécnica de Saúde Joaquim Venâncio, Expressão Popular, 2012, p.687-691.

POLLAK, Michael. Memória e identidade social. Estudos históricos. Rio de janeiro, v. 5. n 10, p.200-212, 1992.

PORTELLI, Alessandro. História oral como arte da escuta. São Paulo: Letra e Voz, 2016.

PRIORI, Angelo Aparecido; PAIXÃO, Letícia Aparecida. A paisagem como fonte histórica e como produtora de memória. História Revista: revista da Faculdade de História e do 
Programa de Pós-Graduação em História da Universidade Federal de Goiás, v. 20, n1, p.158167, 2015. ISSN 1984-4530. Disponível em: https://www.revistas.ufg.br/historia/article/view/31759. Acesso: 18/07/2018.

SANTOS, M; GLASS, V. (Orgs.) Atlas do Agronegócio: fatos e números sobre as corporações que controlam o que comemos. Rio de Janeiro: Fundação Heinrich Böll, 2018.

SANTOS, M. Por uma outra globalização: do pensamento único à consciência universal. Rio de Janeiro: Record, 2004.

SCHAMA, Simon. Paisagem e Memória. São Paulo: Companhia das Letras, 1996.

TUAN, Yi-Fu. Topofilia: um estudo da percepção, atitudes e valores do meio ambiente. São Paulo: Difel, 1980.

\section{Fontes}

Entrevista concedida por Lurdes Zancanaro Manica a Daniele Brocardo. Distrito de Juvinópolis - Cascavel-PR, casa da entrevistada, em 17 de abril de 2018. s/p. 